Journal of Social Sciences 3 (4): 250-259, 2007

ISSN 1549-3652

(C) 2007 Science Publications

\title{
Towards a Theory and View of Teaching Compressed and Abbreviated Research Methodology and Statistics Courses
}

\author{
${ }^{1}$ James Carifio and ${ }^{2}$ Lisa Erikson \\ ${ }^{1}$ University of Massachusetts-Lowell, One University Avenue, Lowell, MA 01854 \\ ${ }^{2}$ Franklin Pierce University, 20 College Road, Rindge, NH 03461
}

\begin{abstract}
One of the highly questionable effects of educational reform and other curriculum reshaping factors at both the high school, post-secondary and graduate levels has been the shift to teaching compressed, pared-down or abbreviated courses in still needed or required subject-matter that became de-emphasized in the current educational reformation. Research methodology, particularly the highly quantitative and experimental kind and statistics, are two still needed to some degree subject matters that has been especially affected by this demotion and compression movement at the pre-service, inservice, professional development, undergraduate, continuing education and graduate levels, even though the professional areas of education, science, business, politics and most other areas (including history) have become far more quantitative and objective research oriented than in the past. Until there are more enlightened policy shifts, effective means of teaching such compressed courses need to be devised and tested, if only to lessen the negative outcomes of such critical courses. This article, therefore, analyzes compressed courses from the point of view of cognitive learning and then describes 5 methods and approaches that were tested to improve the effectiveness of research methodology and statistics courses taught in these formats. Each of the formats helped to reduce student stress and anxiety about the content and its compressed presentation and improved understanding and achievement. The theory and view developed in this article is also applicable to similar compressed courses for scientific and/or technical content which are currently prevalent in allied health and biotechnology areas.
\end{abstract}

Key words: Cognitive learning theory, compressed courses, research and statistics teaching, cartoons, vignettes, learning simulations

\section{INTRODUCTION}

One of the highly questionable effects of educational reform and other curriculum reshaping factors at both the K-12 and post-secondary level has been the shift to teaching compressed, pared-down or abbreviated courses in still needed or required subjectmatter that became de-emphasized in the current educational reformation ${ }^{[1]}$. Research methodology, particularly the highly quantitative and experimental kind and statistics are two still need to some degree subject matters that has been especially affected by this demoting and compression movement at the preservice, in-service, professional development, undergraduate, continuing education and graduate levels, even though the professional areas of education, science, business, politics and most other areas (including history) have become far more quantitative and objectively research oriented than in the past. It may be that much of this statistical and objectively oriented research work is being increasingly outsourced to private research houses, institutes, consultants, companies and agencies, but this outsourcing may in part be the effect of the reform displacement shift that is and has been occurring in the various areas and at the various levels noted above, or/and the movement to education-lite and other alternative forms of research and inquiry, which has resulted in a lack of developing these literacies, knowledges and skills now to even a consumer level of sophistication in many of these areas. Short, compressed and pared down research methodology and statistics course come at a price, however and the price in the long run is a high one. This de-emphasis and resulting gap, moreover, is not the first time this type of reform and reorientation has occurred and with fairly negative results in the long run $^{[2,3]}$ for details.

Several researchers in the last few years have commented on this current teaching problem e.g.,${ }^{[4]}$ and the problems of teaching research methodology and

Corresponding Author: James Carifio, University of Massachusetts-Lowell, One University Avenue, Lowell, MA 01854 
statistics currently in various professional and content areas and the increased difficulties of having to do so in highly compressed and abbreviated delivery formats and courses including both self-directed and on-line formats e.g.. ${ }^{[5,6]}$. In general, these researchers have found that students are less well prepared to take research methodology and statistics courses in terms of basic skills, cognitive literacies and actual first-hand data handling and analyses experiences ${ }^{[4]}$. Additionally, these students tend have multiple demands upon their time and energy and have a difficult time prioritizing and juggling their respective obligations ${ }^{[7]}$ for details, which include:

- Leisure time and recreational activities with friends and family including children.

- Obligations and responsibilities to significant others, which often creates increased stress.

- Stress from the financial cost associated with schooling.

- Conflicts with family and work commitments including travel and emergencies.

- Inability to give $100 \%$ to job or/and family when school requirements intervene.

- Negative educational perceptions and/or unfavorable past experiences.

The last factor, Negative educational perceptions and/or unfavorable past experiences, contribute to the high anxiety levels many students tend to have about research methodology and statistics courses and these high anxiety levels in turn affect motivation, persistence, time-on-task and self-efficacy as well as several other variables Frequent testing (i.e., short feedback intervals), however, tends to help with the aforementioned problems and difficulty ${ }^{[8]}$, whereas course compression does not and tends to exacerbate them, as does behaviorist learning and instructional models $^{[9]}$.

All of the above researchers have called for research on what methods and approaches might be used to improve student learning in compressed mode formats, given that such formats are inherently flawed from the point of cognitive learning theory, but currently very popular formats.

\section{PURPOSE AND METHODOLOGY}

This study is a descriptive study of several methods and approaches that may be used to teach research methodology and statistics in compressed course formats. It is also a qualitative case study of the effectiveness of these different methods and approaches in a compressed course for adult students working fulltime and completing a compressed research methodology and statistics course as part of an undergraduate degree in business (where such a format is currently very prevalent) and in full length versions of the same course for both masters and doctoral level education students. The compressed format for the business students was 5 four-hour class sessions a week apart, which is currently a fairly common compressed format in both business and education and particularly summer and in-service courses in education.

The non-compressed format was 15 two and one half hour class sessions a week apart, which is the typical non-compressed course format for adult learners. It should be noted that the theory and view developed in this article is also applicable to similar compressed courses for scientific and/or technical content which are currently prevalent in allied health, biotechnology, high school sciences and social science areas.

This study will first describe and characterize each method or approached used to compensate for the problems of instructional compression in terms of cognitive learning theory ${ }^{[10]}$ and then give a summary of why the method should ameliorate the problems of instructional compression and be effective. The informal and more formal results obtained with the method or approach characterized and used will then be summarized for each method and format so that all information about each compensatory method and approach may be kept together as a whole.

The methods and approaches that will be reported on here are (1) Cartoons, (2) Vignettes (expanded cartoons), (3) Concrete Experience (use of 3 dimension displays, physical manipulatives and similar experiential activities), (4) Simulation Exercises and (5) Research/Procedure/Analysis Replication (Advanced Simulation). All of these approaches may be done in or outside of the classroom and as group or individual activities, and/or mixtures of these modes, which tends to be best. Also, learning research and statistical knowledge and skills is, in many ways, very similar to learning to write (which is also a key component and phase of both research and statistics) and collaborative and peer-reviewed learning processes are quite effective and can be used to simulate (which is approach 4 above) the collaborative and peer-review components of the research, research review and publication processes.

Cartoons: Cartoons typically give representations of concepts, ideas and principles that are paired down to 
their essential key features and points that are presented relationally as a whole and thus create an instant protoschema that may be expanded, elaborated and developed in subsequent interchanges and instruction. Cartoons are quick and easy to process and tend to surprise you with key insights that become vivid and thus form quick and stronger initial long term memory structures or scaffolding for subsequent information processing and learning. They can also be used to create a strong post-organizing and memory consolidation effect that is probably one of the quickest and simplest over-learning mechanisms there is. Visuals, including cartoons, have consistently been shown to be effective pre and/or post advanced organizers and as effective as verbal ones without visual components in the learning of complex subject matter, with the verbal-visual organizer being the most effective ${ }^{[11]}$.

All over-learning strategies enhance schema formations and strengthening and thus retention of material. Material retention and particularly long term memory retention, is one of the major problems of compressed learning experiences of any kind other than trauma. But trauma has a memory store all of it own, which is why the affective experiences of compressed courses are so well remembered and that memory store is not semantic long term memory, which is the structured repository of subject-matter learning. Cartoons and humor in all forms, moreover, can act to neutralize the negative effect of these courses, which is a simple application of Wolpe's ${ }^{[12]}$ reciprocal inhibition theory, where (small) pleasant experiences can cumulatively neutralize similar negative ones, with the negative ones being the residue of prior experiences and/or the ones in the current learning processes.

A good dose and use of cartoons and humor of various kinds, therefore, can be quite effective in these kind of instructional situations (you can think of them as the dark chocolate factor) and if they are well-chosen and used fairly frequently they can provide distributed practice on the ideas and concepts of the course. The word HAHA, it should be noted, has the Latin root AHA. Consequently, when we unravel or discover new truths for ourselves, or have a flash of deep insight or understanding, we often laugh ${ }^{[13]}$. Distributive practice, therefore, provides numerous opportunities for both AHA and HAHA experiences for students. It follows from these points that cartoons that are well-chosen to foster distributive practice should be processed more deeply and with more sophistication as the course progresses, particularly relative to actual class discussions of them. Anything that facilitates a learner to process information more deeply aids, develops and improves comprehension, which is the gateway to higher order learning. The paucity of theory and research on the use of humor in learning and particularly so in today's schools, is simply astounding, as any quick literature search will show. This particular quick literature search is a good simulation exercise for students to do and particularly as an antidote to the million plus citations one gets on other topics, and, comparatively, it quickly shows that there are still many important areas left to research. Again, the relative quick and dramatic or vivid demonstration of critical concepts, ideas and points is the key idea and theoretical concept here.

One of the difficulties of using cartoon is that one must analyze them very carefully before using them (multiple reviews and opinions are best) as they are, due to their minimalist character and lack of accompanying thick and rich semantic component, to some degree both an ambiguous (in terms of psychological attention and perception processes) and projective (in terms of processing and interpretative processes) stimuli.

As such, a cartoon may have some latent errors about and misrepresentations of concepts, idea, principles and facts of the subject matter that convey and teach misconceptions unconsciously (due to the rapid and holistic processing) that may cause a variety of learning problems from minor to major, both in the instant and later. Cartoons are after all not much different from television ads (and we all love the humorous ones do we not?) in how they work theoretically, particularly if there is no follow-up discussion or activities that make the leaner explicitly unpack the content and meaning of the cartoon, which is a key instructional act and activities in using cartoons to teach.

Nothing is totally obvious or transparent about a cartoon. Humor is, by its very definition, two antithetical representations of something (one dominant and one latent) that collide at some point in a test of some kind (the punch line) that (usually) results in the ascendancy of the latent representation (a very good description of the scientific process, as well as how we are all, like Le Bourgeois Gentiome, coming to understand he had spoken prose all of his life, innate scientists without consciously realizing it) and particularly so every time we laugh.

However, it is strongly recommended that one read Freud's Wit and Its Relationship to the Unconscious to fully understand humor and the use of cartoons and humor in learning, as well as many of the pitfalls one can encounter in using both. For some students encountering humor and cartoons in a research and/or statistics course creates so much cognitive dissonance 


\section{J. Social Sci., 3 (4): 250-259, 2007}

that the technique backfires and interferes with their learning, usually because their anxiety is extremely high and/or they have various rigidities, or are extremely over-focused, or have various views that research and statistics course and particularly compressed one, are not funny, nor the time or place to be humorous or funny at all ${ }^{[14]}$. And some students simply do not see the humor or the point and others are offended by both, which is a difficulty about which one must be very careful.

There is also the problem of keeping the class and particular student disciplined, in-line and moving forward once you introduce humor and cartoons and all of these factors are why you need to have clear grounds rules about appropriate behaviors as well as a clear and explicit stop rule to draw interactions to a conclusion/resolution and move on. So choosing cartoons and using humor wisely and having a graded series of cartoons and humorous examples or stories (as well as testing out the audience in your opening like any good comic does and being prepared to quickly adapt your material and choices) is strongly advised as well as explicit ground and stop rules. Neutralizing these downside factors allows one to maximize all of the benefits of cartoons and humor in these instructional context and particularly compressed instruction.

In general, our experience and findings about using cartoon and humor in two 5 week compressed research and statistics course for undergraduate business students and several such courses for doctoral students in education has been quite positive.

In the compressed research class that Erikson taught, she used cartoons to reduce anxiety, as verbalvisual organizers and to create a strong post-organizing and memory consolidation effect ${ }^{[15]}$ for examples). Some of the feedback she obtained from students included:

- There was great teaching and awesome learning happening, on a tough topic and the cartoons created a lot of the laughter.

- During the breaks, laughter filled the hallways, as an indicator of both our stress release and also of the fellowship that had been created in the classroom.

- When one of us made a mistake, humor helped us get through the confusion and difficult content.

At first, the students were surprised to see cartoons in such a serious class, but they quickly accepted them and then came to expect them. They asked that the cartons be made available electronically to them, which may indicate the cartoons' efficacy as a learning tool.
In the extended classes taught by Carifio, which are more than 20 in number, cartoons were used in the same manner as Erikson with similar results, but they were also used to teach students and doctoral students in particular, to think, analyze, write and work collaboratively as he had the luxury of far more time. Once students started to adapt somewhat to the novelty of the cartoons, Carifio would ask them to list the statistical idea and concepts principles in the cartoon and state how these concepts and principles related together to produce the point or/and joke of the cartoon. He would then have students discuss their work in small groups and together as a large group. He would then extend this use to students producing a written summary of the joke in each cartoon (i.e., embryonic proto-research writing) and he would then introduce control cartoons; namely, cartoons that had errors or misrepresentations of various kinds in them related to statistics, research methodology or/and interpretation (i.e., thinking critically about the content). So with extended time and extended instruction, cartoons can be used to develop proto-research critical analysis skills and proto-research writing skills in a unique, vivid, somewhat enjoyable, collaborative and incrementally small and manageable way. Therefore, learning the baby steps and some of the basics of critiquing research and studies and learning to write research, does not have to be over-whelming, arduous, or too boring and these extended uses of cartoons and responding to the question, Well, what is the joke then can also be used in compressed courses, if only as ice-breakers and warmups to these tasks and skills.

Vignettes: Vignettes are expanded cartoons, which is one of the reasons why various features and factors about cartoons were elaborated in detail above. Vignettes are compressed and carefully constructed stories or narratives of various kinds. The story or vignette may be complete fiction (including science fiction), actual, true and real information, reports and data, or a combination of the two and they should be constructed according to some kind explicit blue-print or protocol more or less like (like an good objective test) that can be validated, if necessary, by an independent panel. Vignettes are so protean and may be adapted and used in so many ways that they are only limited by one's imagination and they may be developed and extended into full-blown case studies of various kinds. One kind of vignette is the simulated (i.e., highly compressed) research study (or study results analysis problem) that is very vivid exemplar of key research and statistical concepts, ideas and principles (and mistakes of various kinds). These 
carefully constructed vignettes can be a graded series of in and out-of-class exercises that increase in complexity and number of factors included along with the check list to score these vignettes, the development of which can be part of the assignment. Such vignettes are linktrainers and can teach concepts, skills and critical understandings in 15 to $60 \mathrm{~min}$ as opposed to the two or three hours it can take a student to read the full study. A student, then can easily read and evaluate 3 times the number of study exemplar per unit time as reading full studies. However, one of the big advantages of vignette studies is that they can require students to complete the analysis of the results as well as write them up along with conclusions and swap their finished work with others in the class for both checking of the analyses and a critique of the write-up and conclusions.

So vignettes can be used to simulate the research process itself concretely in a variety of different ways.

The theory of vignettes, as well as the procedures for developing them and validating them if necessary and the various kinds of sophisticated empirical data and findings that may be obtained through using them to do research is described in great detail elsewhere $^{[16,17]}$. Therefore, using vignettes to teach research and statistics not only is a fast and effective way to teach this subject matter and a broad array of its concepts, ideas, principles and skills, but it also has the additional benefit of laying down the foundations of and teaching a very powerful and extremely versatile mixed-methods research methodology, as vignettes combine qualitative and quantitative research together into a combined and integrated whole. So vignettes are the perfect quick exemplar and concrete simulated experience of most of the key features of a true experiment and data analysis, but they stop (by shortcircuiting) and resolve many aspects, features and arguments of the quantitative-qualitative (non) debate by vividly demonstrating that they are not either/or methodologies or approaches, which is incredibly time saving if nothing else. Vignettes, then are indeed the missing link of concretely, vividly and practically teaching research methodology and statistics quickly, efficiently and effectively as they are relative smallscale as opposed to large-scale or full-blown simulations or the real thing. And they are also a link trainer for preparing students to read actual research studies.

The website Carifio ${ }^{[15]}$ contains an example of a simple real-life research vignette that was used in the first class of the compressed course to (a) reduce anxiety, (b) demonstrate the prevalence, use and misuse of statistics in every day life and the media and (c) to introduce the topic of correlation versus causation. It is a vignette that tends to get students talking and debating with each other and all side of the debate shocked and surprised by the research methodology and statistical mistakes in the study that they missed, did not know or led them to reason fallaciously.

Other vignettes begin with the key features of a true experiment and report organized into a hierarchical checklist of importance (itself a group project for doctoral students). This full checklist (model) is abbreviated for each kind of research and research design there is. Therefore, a correlation study is missing the key feature of systematic and explicit manipulation of the independent variables(s) by the researcher(s), which has various consequences. Vignettes can be systematically written including or excluding each of the key features on this checklist and given to students to read and analyze which features are present and absent in specific terms of the information in the vignette and what the consequences are relative to the studies conclusions and so on. Vignettes may be written that stop at the analysis section of the methodology section and ask the students to state how the data should be analyzed and why. Other vignettes, with highly compressed sections up the results section, could ask students to complete ANOVA tables and write the results and conclusions ${ }^{[15]}$ for an elementary and intermediate example). Writing up the results of analyses (according to APA standards) is one of the skills all students have a great deal of trouble with and a great deal of trouble learning, leading to endless agonies in their dissertations and beyond. Vignettes are an extremely quick and efficient method of training students to write up results and conclusions of different kinds of studies through practice, practice, practice and the peer review process and method of teaching writing (and revision) collaboratively. A few examples of these kinds of vignettes are given at the website Carifio ${ }^{[15]}$.

Concrete Experiences: As Piaget pointed out and Elkin and others later empirically documented, only about $50 \%$ of the population reaches the stage of formal reasoning in Piaget's model of the development of logical thinking in people. This fact is problematic enough except the problem is even worse than that. A person who has reach the stage of formal reasoning in one subject-matter area may not be a formal reasoner in one or more other subject-matter areas; namely, the attainment of formal reasons is not a global or across the board stage of development, but rather it can and most often is lumpy and something that is not necessary homogeneous. With the avoidance of mathematics and science courses by students in our culture prior to educational reform and the less and less contract people 


\section{J. Social Sci., 3 (4): 250-259, 2007}

have with the concrete and real world in our electronic and media driven culture, students today taking research methodology and statistics courses tend to be at the concrete operations level of development in these two subject-matter areas. Students in this area, therefore, tend to be in great need of Montessori Enrichment relative to the concrete referents for many ideas, concepts and principles and real world as opposed to virtual examples of a wide variety of things that make up the actual world or research methodology, instrumentation and statistics. And these students also need to be taught many things as one would teach students at the concrete operations level of development and that includes mathematics and mathematic concepts and ideas.

Use of 3 dimensional displays and concrete manipulatives to teach research processes and statistical concepts through vivid visuals representations that the student may actual build using concrete operations and simulated procedures is key to their learning and truly and deeply understanding a wide variety of concepts, principles and statistics. One of us (Carifio) has developed a large number of 3 dimensional displays and concrete manipulatives for teaching statistics and research methodology. But a simple checkers board and large box of checkers of many colors that the labels for the units of measurement/observation (numbers or otherwise) can be pasted on can be used to have students concretely construct distributions of samples of data as well as correlations in 3 dimensions that will quickly and likely (like cartoons) illustrate each idea and assumption and the consequences of assumption violations in all descriptive statistics and correlations. Counting the number of overlapping cases between two distributions can also get one into comparative testing and so on.

The point here is that the concrete processes and manipulations and the visualization of the whole that is not apparent in graphs or two dimensional displays leads to rapid and deep understanding and insight and the creation proto-schemas just like cartoons that can be extended and elaborated. For example, the concept of homo or heteroscedacicity of regression and its relationship to errors of prediction or forecasting can be visually shown three dimensionally with a checker board and checkers and understood and with some sophistication with absolutely no numbers. Mathematizing the visually observable facts into actual numbers after the vivid and quick demonstration is usually much, much easier than without the visual depiction and demonstration. Use of concrete depiction and concrete simulations also builds the foundations needed for the transition to more symbolic simulations for most students.
Simulations: Simulation exercises, such as building Excel spreadsheets to run and change numbers and observe what happens and draw some generalizations, are expanded vignettes that add in a time and a dynamic or unfolding factor and increasing levels of complexity. One can use Excel, both in and out of class, that form a mini or mico lab to teach and prove by actual demonstrations (observational learning) various statistic concepts, principles, rules, facts and laws or theorems ranging from what happens to various statistics and displays if data is added or subtracted to a sample, sampling distribution and sampling errors, that the mean of a sample is uncorrelated to its variance, correlations between random samples that are just sampling error and so on. There is some software available currently that will do various simulations and some textbooks that include such software as well as data sets with the textbook, but it is an area that needs more and better software to be developed according to a guided experiment and play with the data and see what happens design point of view (guided discovery is always more effective than unguided discovery when it comes to learning), as well as systematic exercises and labs for students to do both in and out of class. However, a great deal can be done with Excel if you install the FULL VERSION off the disk that has all of the statistical functions, advanced statistical functions, graphing functions and tools such as random number generators and random selection functions. The "normal installation" of Excel does not install all of these wonderful capabilities of Excel, which is why many people do not know about all of these capabilities of Excel and Excel as a very simple and fairly quick link trainer for SPSS, SASS, or other sophisticated and complex software packages that take some time to master and understand how to use. The full version of Excel can analyze the data from the vast majority of quantitative or qualitative studies that most students tend to do or tend to do as a learning experience.

Aspects of simulations with Excel that are very helpful to students are changing the basic data in the spread sheet (data set) and seeing what happens to the resulting statistics and graphs. The choosing of ways and strategies to alter the data and being able to alter the data and see the results rapidly and the interplay between the numeric indicators (and representations) and the graphic indicators (and visual representations) at the same time creates intuitive and latent connections and understanding for students relative to grasping the gestalts and patterns of unorganized and organized and indexed information, as well as the effects of sample size. This point is particularly true for novice students, who tend to be quite surprised by how many 


\section{J. Social Sci., 3 (4): 250-259, 2007}

observations they have to change in a sample of size 200 to get sizable and significant changes in the resulting numeric and graphic representations. This intuitive insight approach is particularly powerful for correlation where you can have students do various things by simple counting procedures (i.e., number of one-to-one correspondences) and have the spreadsheet forecast (predict) subjects' Y scores and how they differ from their actual (observed) Y score. Students can then count the number of actual hits and misses (which is the explained variance), use this information to compute the correlation, make a distribution of the prediction errors, which will have mean of zero and compute the standard deviation of the prediction errors distribution, which is the standard error of prediction: all in concrete observable terms and rapidly as it is not being computed by hand, although a few simple hand computations are typically highly effective with most students and should note be neglected as a strategy and approach.

Carifio has found that the spreadsheet or lab that is very powerful and effective is the one that can be done on demonstrating and proving all of the facts and fine points about the standard error of sampling (in both uncorrelated and correlated form), which is the heart of statistical theory and analysis. Excel will generate 5 random samples of size 5 and compute all of the descriptive statistics for each and then use these to generate the sampling distribution for each statistic. It will then do the same thing on a new sheet for 5 random samples of size 10 and then another new sheet for samples of size $15,30,50,75$ and 100 . It will build a list of the standard error of sampling for each sampling distribution and do a simple plot which shows it to be non-linear. However, you can also make a list of the means and standard deviations for all of the samples that you have randomly drawn and do the correlation between the two which will come out to be zero, which is the most important and critical fact in all of statistics. You can also go to the 10 random samples of size 5 your drew and do a correlation between each random sample and all of the others and you will see sizable positive and negative correlations in the matrix as well as zero order ones, when theoretically they all should be zero, if there as no such thing as sampling error or the artifacts it creates. But as the sample size increases more and more of the correlations in the matrix are zero until you get to the point where at least $95 \%$ are zero. These empirical demonstrations and observing these events and proving these things to oneself are often so powerful for some students that it turns them $180^{\circ} \mathrm{C}$ from being anti-statistical and anti-numbers to being just the opposite. There is very, very little mathematics involved in these demonstrations and proofs whicha re primarily logical, observational and experimental, which is the best part of this simulation exercise; namely, that one is conducting an experiment and the experiment one is conducting is an exemplar of a true experiment. This particular simulation exercise is a great one to do as a group exercise so that students can discuss and argue about procedures and results as well as compare their results to those of the other groups in the class, which teaches the concept of replication of results in a very dramatic way. Examples of spreadsheets such as the one described above are given at the website Carifio ${ }^{[15]}$ for random samples of size 5 and 15. However, such spreadsheets are better appreciated when they are dynamic on the screen rather than static on the printed page, although they may be effectively used in static form too.

Once can move from spreadsheet inquiries, demonstrations and proofs to actually analyzing data sets beginning with the cartoon form, which is the form of most of the data that comes with textbooks, to forms that are more vignette-like in character, with the vignette providing contextualizing information that is more thick and rich than the cartoon form such as some specific research questions or hypotheses or even a simple theory of sorts that the student or the student group needs to figure out how to test to confirm or deny the theory in question. The data one uses for such simulation exercises may be fictionalized or real, but one needs to be both cautious and circumspect in using real data with students for several different reasons, which can be turned into lessons on rights of human subjects. Real data, however, can be easily "fictionalized" in a variety of ways (e.g., changing all of the variable names and having no subject identifiers), which is often a wise thing to do these days.

In compressed courses, the elementary simulations described above are usually effective in-class demonstrations because they are quick, vivid and can be used to get students to be interactive with the instructor and each other rather than passively listening. It is best to have such spreadsheet pre-built, rather than having students fumbling over learning the mechanics of spreadsheet, getting frustrated and wasting time of such things, as time is the precious resource. But one can use less elementary simulations outside of class as homework and as group projects and out-of-class learning activities, particularly in situations where students may meet without a great deal of difficulty and even in these situations they can do out-of-class simulations as group via the web. In longer and more extended courses, such simulations may be routinely integrated into in-class and out-of-class activities and a 
portion of every other class can be used as a minisimulation-lab for either doing the simulation or having follow-up discussions about it and the results obtained. Having regular times where students talk procedures, data, results and conclusions (i.e., talk shop), as part of an informal micro-conference builds their identity as researchers and data analysts, as well as a sense of the value of research support and community. These kinds of initial socialization processes are routinely done for novice teachers and other professionals, so the questions is why are we not doing the same kinds of socializing activities for novice researchers. Lastly, simulations individually or collectively are steps towards replicating studies and/or analyses of complex data sets.

Replications: Replicating a study can be, without doubt, a very effective way to learn to do research and analysis, even given that there are a great many logistical problems to be attended to and controlled (access, time, costs and so on) in such a project or activity. It is often pointed out that in education and the social sciences studies are rarely replicated, which they need to be to assess the reliability and reproducibility of their findings, so there is a potential common good and benefit to be obtained from such activities. It should be pointed out that to this day, one of the major ways that writers, painters and sculptors learn their skills and crafts is by imitating and replicating the works of the great masters in their area, thereby building up their repertoire of the various forms and best practices in their area. Replication studies also tend to put one in an apprenticeship position and relationship with a more expert supervisor, which has a long standing and fairly successful tradition in the sciences, at least, if not elsewhere.

There are many very quick and simple studies that may be replicated that require very few subjects ranging from qualitative observations in the park (literally) to simple memory and cognitive processes experiments, which can be done in less than 15 min with just the subjects in the class. Again, students may do these individually or pool their efforts and data. The replication should line-up with all of the parts and considerations in doing a research study as well as the actual report or article on the studies being replicated. One really interesting and informative part of doing a replication is figuring out exactly what to do and exactly how to collect, code and analyze the data to compare one's results to the original. This aspect of replication not only stimulates extremely close readings of the study, but also deep insights about the typically unrecognized silences and absences of (desired) information in the study being replicated. One of us (Carifio) has found that students who have to replicate studies tend to quickly become advocates of reporting standards and standard reporting protocols.

Another simple replication is to redo an interesting (simple) survey. This replication tends to bring all of the parts together into a whole (without having to re-invent the wheel) and gives the procedural experiences and dimension needed to understand the insides of research, as well as various surprises and insights when comparing the results obtained to the original results. This task may be done as a group project (division of labor and cooperative learning) or individually depending on goals and objectives. Dissertations are often a good source of such simple surveys and give the added advantage with graduate students of getting them to actually read a dissertation, and, if the instructor is savvy, updating its literature review. If the context allows, one can also encourage the student to add one new feature to the study being replicated to either improve it or/and answer an additional question. Having students replicate studies, however, can be fraught with difficulties just now, as many Institutional Review Boards are claiming that they must first review and approve the replication, which make replication impossible to do in compressed courses, without some kind of blanket a priori approval procedure before the course is even conducted of studies $\mathrm{A}, \mathrm{B}$ and $\mathrm{C}$ and next to impossible to do in longer and full-length courses.

The compressed 5 week course with adult business students one of us taught (Erikson) was going to have students in the course replicate a survey study done about the factors that affected adult students' persistence in and graduation from continuing education degree programs similar to the one in which they were enrolled, as opposed to having each student develop, administer, analyze and report a unique survey of their own, which was the traditional project used in the course. Students were not only high interested in replicating the survey and very enthusiastic about the replication as compared to the traditional course project, but quickly realized how much less frustrating and more efficient replicating the study would be for them than the traditional course project. Replicating the survey served as a course focus for these students as the various ideas, concepts, principles and points that were being discussed in class to in the end could be concretely and quickly related to the survey that these students were going to replicate. Unfortunately, this group could not carry out the actual replication during the course, as the college's new IRB officer declared that the survey would have undergo IRB review (after 
saying the replication was OK), which could not be done before the course was over. Students, therefore, had to reanalyze the original data from the survey, which fortuitously was available. In longer courses, highly focused replications have been successfully used by Carifio and particularly as an apprenticeship-like experience for students prior to their developing their dissertation proposals. Replication, however, are labor intensive and this point should be clearly noted.

\section{DISCUSSION AND CONCLUSIONS}

Teaching compressed courses is a difficult task, but teaching compressed research methodology and/or statistics courses is a particularly difficult task for several reasons. First, learning takes time and particularly learning that is developing new schemas for students that often involve the unlearning and/or revision of old schemas before the new schemas can be appropriately developed. Next is the factor that the old schemas that must be unlearned may be emotional schemas and their associated attitudes and behaviors (or phobias of various kinds) and not just cognitive schemas. Next is the factor that learning complex, interrelated and cumulatively hierarchical material (and not getting lost, frustrated and confused doing so) takes a lot of time that incorporates lots of review and connections-makings to build appropriate and wellstructured conceptual schemas as opposed to poorly structured, shallow and functional ones ${ }^{[18]}$ for details). Lots of time is also required if the subject-matter or material to be learned is controversial or disliked by students $^{[19]}$ and lots of time is required is the learning involves acquiring complex sets of inter-related skills ${ }^{[20]}$. The very idea that the time to learning things can be compressed and the learning process can be made highly efficient is a behaviorist concept and view emanating from the time and motion work studies in industry at the turn of the century to the grandiose claims and arguments of Skinner ${ }^{[21]}$ in his various books on teaching machines and Gagne's ${ }^{[22]}$ counter arguments to Piaget's claims that (complex) learning (and development) cannot be rushed or accelerated very much. There is the persistent and prevailing myth of the crash, crammed or compressed course in American Education, perhaps a view left over from the Pioneer and Frontier Days and that learning can be made highly efficient in various ways without any loss or sacrifice in the sophistication or quality of outcomes or long term collateral damage of various kinds.

Learning indeed can be made relatively more efficient to some degree without loss of quality of outcomes, if quality strategies are used, but it is the extreme and behaviorist forms of this view that are the myth and the problem and particularly in the context of more complex subject-matter and post-secondary education courses where the dangers of ending up with content-lite courses that have little long term retention is extremely high with many long term professional consequences. Unfortunately, all of these problems are particularly severe in the area of the teaching research methodology and statistics (as well as business and science courses), where there has been a long and strong historical association between radical behaviorism, blind empiricism and a focus on efficiencies and yields. Given these points, we have tried in this article to focus on some general strategies and approaches that can be used in compressed courses to compensate for various difficulties compression creates and improve the quality of learning that occurs in both compressed and full-length courses that come from cognitive learning theory.

In general, students found each of these approaches helpful and effective in different ways and for different reasons depending on their backgrounds and prior preparation. Humor was found to be a particularly effective strategy. Nine ways in which humor can help teachers to achieve educational goals, in both compressed and non-compressed classes are that it (1) attracts attention and provokes thought, (2) liberates creative capacities, (3) motivates and energizes, (4) improves communication, (5) soothes difficult moments, (6) solves problems, (7) increases quality and quantity of students' reading, (8) reinforces desired behaviors and (9) has entertainment value ${ }^{[23]}$. Also, there are wonderful physical effects of humor, including deeper breathing and stress reduction ${ }^{[13]}$. So, the targeted use of humor in the culture of a classroom can be highly effective. One must be careful in different ways in using humor in teaching, but the key is to make sure that you do not shut off humor as a teaching tool and strategy but try rather to capitalize on it.

Less well prepared subjects, found cartoons, vignettes and manipulatives very helpful, whereas the better prepared subjects found the simulation and replication more helpful. Doing the first 3 methods were easy for students in the compressed course format, whereas the last two were more difficult for them, but much easier in the non-compressed course format. Vignettes were found to be the most flexible, adaptive and versatile of the five strategies as well as the easiest to develop quickly and use without a large investment of time and resources. Students in particularly liked the more abbreviated vignettes and liked doing them in class as either a pre or post instructional activity. Those used to help students develop skills of doing and 
checking analyses and writing up results were particularly well liked. Elementary simulations and replications were liked and popular, but as both became more complex or sophisticated (and more labor intensive to both develop and do) many students found them to be a lot of work and somewhat overwhelming. Doing more complex and sophisticated simulations and/or replications as a group activity and project (and spreading the talent in the class across the groups) is advised as a strategy for managing these latter difficulties.

\section{REFERENCES}

1. Aiken, J., 2004. Reflections of teaching research and statistics courses since educational reform. Paper presented at the annual conference of the Eastern Educational Research Association. Sarasota, Fla.

2. Tiegs, E., 1929. Tests and Measurements for Teachers. University of Chicago Press.

3. Kniefel, D. and S. Dinkham, 1970. A survey of educational measurment and statistics books. J. Edu. Measure., 1 (2): 63-71.

4. Johnson, E., 2001. Factor affecting students learning in statistics courses. Paper presented at the annual conference of the Eastern Educational Research Association. Tampa, Fla.

5. Mayo, R., 1962. Pre-Service Preparation of Teachers in Educational Measurement and Statistics. US Office of Education.

6. Williams, T., 2003. Current trends in professional education and professional development training. Paper presented at the annual conference of the Eastern Educational Research Association. Hilton Head, SC.

7. Stewart, T., 2002. The relationship between MyersBriggs type profiles and key factors that affect academic program completion. Doctoral Dissertation completed at the University of Massachusetts at Lowell.

8. Norton, R., 2004. Improving students' learning in introductory statistics courses. Paper presented at the annual conference of the Eastern Educational Research Association. Sarasota, Fla.

9. Wilson, 2005. Designing better introductory statistics courses for educators. Paper presented at the annual conference of the Eastern Educational Research Association. Hilton Head, SC.
10. Carifio, J., 2005. An integrated information processing theory of learning. Proceedings of the Eighth International History, Philosophy and Science Teaching Conference, Leeds, England, pp: 100-172. < <ttp://www.ihpst2005.leeds.ac.uk /papers/Carifio.pdf $>$.

11. Bergen, D., 1992. Teaching strategies: Using humor to facilitate learning. Childhood Education, 69 (2): 105-106.

12. Wolpe, J., 1958. Psychotherapy by reciprocal inhibition. Stanford, CA: Stanford University Press.

13. Gal, I. and L. Ginsburg, 1994. The role of beliefs and attitudes in learning statistics: Towards an assessment framework. J. Stat. Edu., 2 (2): 26-35.

14. Civikly, J.M., 1986. Humor and the enjoyment of college teaching. New Directions for Teaching and Learning, No. 26 (Communicating in College Classrooms), pp: 61-70.

15. Carifio, J., 2007. Examples of Cartoons, Vignettes, Manipulatives and Replications for Teaching Compressed Research and Statistics Courses. http//gse.uml.edu.carifio.

16. Carifio, J. and M. Lanza, 1992. On the need to use control vignettes in social science research. Work: J. Prevention Assess. Rehabilitation Winter, 2 (3): 28-38.

17. Carifio, J. and M. Lanza, 1995. Empirical findings on the external validity of patient assault vignettes. Work: J. Prevention Assess. Rehabilitation, 5: 265-276.

18. Novak, J.D. and D.B. Gowin, 1996. Learning to Learning. Cambridge University press, New York.

19. Carifio, J., 1991. Preparing teachers attitudes toward tests and testing. Paper presented at the annual conference of the Eastern Educational Research Association, Miami, FLA.

20. Ashcraft, M.H., 2004. Cognition 4th Edn. PrenticeHall, New York.

21. Skinner, B.F., 1953. Science and Human Behavior. McMillan, New York.

22. Gagne, R., 1976. The Conditions of Learning. Holt, Rinehart and Winston, New York.

23. Meyer, R., 2003. Learning and Instruction. Prentice-Hall, Upper Saddle River, N.J. 